\title{
Endophytic fungi as indirect defense mechanisms in grasses - mycotoxins enhance the UV-visibility of herbivore urine in the eyes of predators
}

\author{
SUSANNA SAARI ${ }^{1}$, OTSO HUITU ${ }^{2}$, MARJO HELANDER ${ }^{1}$, \\ PÄIVI LEHTONEN ${ }^{1}$ and KARI SAIKKONEN ${ }^{3}$ \\ ${ }^{1}$ Plant Protection, Agrifood Research Finland, 31600 Jokioinen, Finland \\ ${ }^{2}$ The Finnish Forest Research Institute, Suonenjoki Research Unit, Juntintie 154, 77600 Suonenjoki, Finland \\ ${ }^{3}$ MTT, Plant Production Research, Lönnrotinkatu 3, 50100 Mikkeli, Finland \\ susanna.saari@mtt.fi
}

Endophytes are known to increase the resistance of their host plant to voles directly through reduced palatability. In our research we propose that endophytes might also have indirect mechanisms to increase plant resistance against mammalian herbivores. Plants produce chemical compounds which make urine markings of mammalian herbivores visible to their avian predators. We tested experimentally a novel hypothesis which predicts that mutualistic fungal endophytes of grasses may enhance the UV-visibility of vole urine in the eyes of their avian predators. We found that field voles (Microtus agrestis) feeding on endophyte-infected meadow ryegrass (Lolium pratense ex. Festuca pratensis) lost body mass significantly over the experimental period of 2 days, while voles feeding on non-infected meadow ryegrass gained mass. Interestingly, the intensity peak of UV-fluorescence in the urine of voles feeding on endophyte-infected grass shifted from $>380 \mathrm{~nm}$ to ca. $370 \mathrm{~nm}$, which is the suggested maximum sensitivity of the UV pigments in the eye of vole-eating raptors. Therefore, grazing on endophyte-infected grasses may enhance the UV-visibility of vole urine to their avian predators. To our knowledge, this is a unique demonstration of indirect plant defense mechanisms employing predators of mammalian herbivores. 